\title{
Aspergillus flavus virulence in pods and seeds of peanut with different drought responsive genotypes related to water status
}

\author{
Waraluk Senakoon $^{\mathrm{a}}$, Suporn Nuchadomrong ${ }^{\mathrm{a}, *}$, Pornpimol Jearranaiprepame ${ }^{\mathrm{b}}$, Gulsiri Senawong ${ }^{\mathrm{a}}$, \\ Sanun Jogloy ${ }^{c, d}$, Patcharin Songsric ${ }^{\mathrm{c}}$ \\ a Department of Biochemistry, Faculty of Science, Khon Kaen University, Khon Kaen 40002 Thailand \\ b Department of Biology, Faculty of Science, Khon Kaen University, Khon Kaen 40002 Thailand \\ c Department of Agronomy, Faculty of Agriculture, Khon Kaen University, Khon Kaen 40002 Thailand \\ d Peanut and Jerusalem Artichoke Improvement for Functional Food Research Group and Plant Breeding \\ Research Center for Sustainable Agriculture, Khon Kaen University, Khon Kaen 40002 Thailand
}

*Corresponding author, e-mail: suporn@kku.ac.th

Received 6 Jun 2020

Accepted 30 Jan 2021

\begin{abstract}
Drought resistance traits are important for resistance to preharvest aflatoxin contamination in peanut seeds caused by Aspergillus flavus; however, the evidence has been controversial. The problem might be solved by investigating fungal activities relevant to drought effects on the early pod. Herein, drought impacts on three peanut cultivars with different genotypes were shown as leaf adaptation to reduce transpiration. High impacts were observed in ICGV 98300, ICGV 98308, and Tainan 9 cultivars. Fungal ingress was not histologically found across sclerenchyma to the inner parenchyma of R3 pod pericarp regardless of genotypes or water conditions. Similar activities occurred in R5 pods of non-drought stressed control plants, and the fungus was not detectable inside newly developing seeds. Healthy sclerenchyma likely displayed a physical barrier role. Drought led to the fungal detection in seeds of the three cultivars. The results corresponded to the fungal germination tests in mature seeds, where A. flavus was found, of stressed plants. A. flavus nor-1 transcript was occasionally detected showing A. flavus colonization in a number of R5 kernels of control plants. Under drought condition, the nor- 1 expression was increased by 2.5 folds in Tainan 9 and ICGV 98300, and a small increase was observed in ICGV 98308. The reducing sugar contents in R5 kernels of Tainan 9 and ICGV 98300 were also increased, suggesting the stimulation of oxidative stress and aflatoxin synthesis. High A. flavus virulence, based on nor-1 expression and reducing sugar content, was remarkable in ICGV 98308 under water regimes for control and drought-stressed plants under greenhouse conditions.
\end{abstract}

KEYWORDS: Arachis hypogaea, Aspergillus flavus, drought impact, pod histology, nor-1 expression

\section{INTRODUCTION}

Aspergillus flavus is a soil saprophytic filamentous fungus [1], which is causative for aflatoxin production in oil-rich seeds and grains [2]. Many countries have regulation limits for aflatoxins due to aflatoxin toxicosis in human and livestock [3]. Aflatoxins are synthesized by a secondary metabolism which uses acetate as a precursor and has norsolorinic acid (Nor) as a key intermediate [4]. An A. flavus specific aflatoxin promotes liver cancer in hepatitis $B$ virus infected patients [5]. Aflatoxin contamination in food and feeds is, therefore, a big concern and several detoxification methods have been studied. The attempt to detoxify aflatoxin by degradation using a culture of Cladosporium uredinicola has been recently reported [6].
Peanut (Arachis hypogaea L.) produces fruits or pods under soil surface at the depth of about 5$10 \mathrm{~cm}$. It favors rather warm and hot climates [7]. Peanut is cropped in light sandy soil to facilitate manual pod harvest. Waterlogging is unfavorable and can cause pod damage by soil organisms which prefer damping $[7,8]$. The main production of peanut is from the semi-arid rainfed areas in the tropical zone of Africa and Asia [7]. Peanut plants are unpredictably at risks of drought during crop season. Low pod yield is obtained when drought effect prolongs in reproductive stage [9]. Before harvesting, drought also increases the number of A. flavus infected pods and aflatoxin concentration in pod kernel [10]. The induction of A. flavus infection and aflatoxin synthesis is proposed to involve the loss in pod moisture bringing about less biosyn- 
thesis of pod defensive biomolecules $[11,12]$. Resistance to aflatoxin contamination can be resistance to A. flavus penetration across pod shell and/or seed coat, and resistance to the fungal growth and toxin synthesis in kernel [13-16]. Under drought condition, planting resistant peanuts did not guarantee low aflatoxin level in mature seeds $[10,17,18]$. It is still not clear about the mechanisms of preharvest A. flavus virulence. Pod develops defined tissues during maturation [19]. Pericarp of the beginning pod displays a nutrient reservior to support seed development, and it is dehydrated to become pod shell [20]. Seed coat is present early in the beginning seed. For resistance to A. flavus infection, mature seeds bear advantageous seed coat structures and defensive components [16]. Histological study can help understand the mode of fungal ingress in pod tissues related to susceptibility or resistance to A. flavus. It is also informative, but little study has been done, to investigate the fungal virulence in association with its invasion progress and with drought stress. An aflatoxigenic fungus, A. parasiticus, harboring nor-1 promoter-GUS reporter gene was previously used to demonstrate nor-1 expression and fungal proliferation in mature pods [21]. A. flavus could be detectable in fungal germination tests with gynophore (or peg) punctured into soil and with seeds at the beginning of maturity stage [22]. The present work gave additional evidences of A. flavus virulence during the gap period of both stages (the peg stage and the beginning seed maturity stage) and the drought effect. Drought resistant peanuts with different genotypes were studied and results were compared to understand the fungal virulence.

\section{MATERIALS AND METHODS}

\section{Plant management}

Pot experiments were undertaken using ICGV 98300 and ICGV 98308, drought resistant peanuts from the ICRISAT germplasms (India) [17], and Tainan 9 which is widely cultivated in Thailand. Soil water holding was routinely analyzed to monitor watering at soil capacity for the control groups and at $1 / 3$ capacity for severe drought treatments. Plantings were set up in Randomized Complete Block Design (RCBD) with four replications under greenhouse conditions at the Field Crop Research Station, Khon Kaen University. Four plants were grown in a pot. At 5.00-6.00 p.m. daily, water was given on soil surface to compensate the calculated water loss [23]. In drought treatment, four plants were individually grown in four pots, and watering was stopped a few preceding days to generate drought at the beginning pod (R3) stage [19]. Then, watering was restricted to maintain the drought until harvest time. At the beginning bloom (R1) stage, which was 20 days before drought initiation, a water suspension of $1.75 \times 10^{7}$ spores of virulent $A$. flavus [10] from fresh cultures on potato dextrose agar (PDA) medium was applied over the soil surface and followed immediately by daily watering.

Healthy appearing pods were collected from the control plants and the drought treated plants both at the stages of R3, R5 (beginning seed) and R8 (harvest maturity). Pods were washed and used in further experiments.

\section{Evaluation of leaf responses to soil water content}

Leaf responses were evaluated at R3 and R5 stages. A second expanded leaf in the main stem apex of a plant in each pot was determined for SPAD chlorophyll meter reading, SCMR, as an indicator of photosynthetic efficiency [23] at 11.00-12.00 a.m. by a Minolta SPAD meter. The third leaf was detached to measure leaf area by a LI-COR Area Meter (LI 3100C), and dried in an oven at $80^{\circ} \mathrm{C}$ to obtain dry weight. The leaf area and dry weight were used to calculate specific leaf area (SLA; $\mathrm{cm}^{2} / \mathrm{g}$ ) for indicating leaf thickness [23]. High SCMR indicates high photosynthetic efficiency and low SLA implies thick leaf which reduces plant transpiration.

\section{Histological study for A. flavus ingress in pods}

R3 and R5 pods were fixed for a week in formaldehyde-glacial acetic acid-absolute ethanol solution $(1: 1: 1 \mathrm{v} / \mathrm{v})$ followed by dehydration for 10 min each in ethanol series of $70 \%, 90 \%, 95 \%$, and $99.9 \%$. Then, the pods were embedded in paraffin and transversely excised to $10-\mu \mathrm{m}$ thick sections which were, then, mounted on glass slides. The sections were deparaffinized by 30 -min washings with two changes of xylene, and rehydrated by dipping twice for $10 \mathrm{~min}$ each in series of ethanol (99.9\%, 90\%, 70\%, 50\%, and 30\%) and distilled water. Fungal stain was firstly made overnight with $5 \%$ lactophenol cotton blue dye solution. Removal of residual dye was modified from the previous procedure [24] by subsequent washings for 1 min twice in distilled water, $5 \mathrm{~min}$ in 20\% glycerol, and $1 \mathrm{~min}$ in distilled water. Secondly, plant cells were counterstained for $20 \mathrm{~s}$ by $1 \%$ safranin $O$ [25], and the sections were then washed as aforementioned. The sections were inspected and photographed under a 
light microscope. Pod tissue layers were defined following previous descriptions [21].

\section{RNA extraction and study for nor-1 gene expression by RT-PCR}

Kernel of three R5 seeds was individually subjected to RNA extraction and DNase digestion by QIAGEN RNeasy Plant Mini Kit protocols. Reverse transcription for cDNA synthesis was performed with $1 \mu \mathrm{g}$ of the RNA and oligo $(\mathrm{dT})_{18}$ primer according to the instruction of Roche Transcriptor High Fidelity cDNA Synthesis Kit. Random hexamer primer available in the kit was used to synthesize cDNA for PCR of $18 S$ rRNA as a normalized RT-PCR.

This study used nor-1 primers (forward primer: ACGGATCACTTAGCCAGCAC and reverse primer: CTACCAGGGGAGTTGAGATCC) which were previously designed from $A$. parasiticus nor-1 cDNA [26]. The 18S rRNA primers (forward primer: ACAAT ACCGGGCTCAAACGA and reverse primer: CAAT TAAGGCCAGGAGCGTATC) were designed from Arabidopsis thaliana 18S rRNA cDNA (GenBank accession no. X16077.1). The amplification was performed with $400 \mathrm{ng}$ of the cDNA template in a 50- $\mu 1$ mixture $(1 \times$ PCR buffer, $0.4 \mu \mathrm{M}$ of corresponding primers, $1 \mathrm{mM} \mathrm{MgCl}, 0.2 \mathrm{mM}$ dNTPs, and 2.5 units of Taq polymerase). PCR program included pre-denaturation at $94^{\circ} \mathrm{C}$ for $5 \mathrm{~min}, 25$ cycles of amplification (denaturation at $94^{\circ} \mathrm{C}$ for $1 \mathrm{~min}$, annealing for $30 \mathrm{~s}$, extension at $72^{\circ} \mathrm{C}$ for $1 \mathrm{~min}$ ), and final extension at $72^{\circ} \mathrm{C}$ for $5 \mathrm{~min}$. The annealing temperatures were $56^{\circ} \mathrm{C}$ for nor-1 primers and $54^{\circ} \mathrm{C}$ for $18 S$ rRNA primers. The PCR product was analyzed by $2 \%$ agarose gel electrophoresis [27]. The expected nor-1 amplicon was sequenced by the Biomolecular Analysis Service Unit, Khon Kaen University. The sequence was aligned to that of $A$. flavus nor-1 cDNA (GenBank FN398172.1). Band intensity was measured by GeneTools Program installed in a SYNGENE G:Box F3 Gel Doc, and relative intensity was obtained by comparing to that of the detectable band in Tainan 9 under non-stressed watering.

\section{Test for A. flavus contamination in mature seeds}

Seeds at harvest maturity (R8) were surface sterilized by $70 \%$ ethanol for $30 \mathrm{~s}$ followed by shaking in $1 \%$ sodium hypochlorite for $5 \mathrm{~min}$. After washings in sterile distilled water, seeds $(n=10)$ were incubated on PDA for a week at $30^{\circ} \mathrm{C}$. Mycelia producing yellowish green spores were observed for A. flavus proliferation [2]. (a)
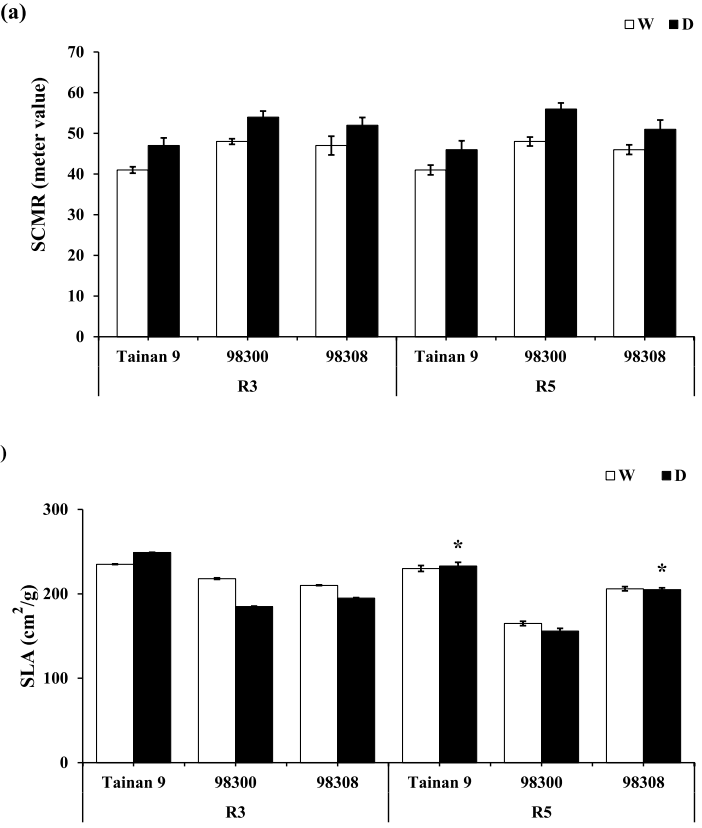

Fig. 1 Leaf physiology including (a) SCMR and (b) SLA of peanut plants at R3 and R5 stages in control (W) and drought (D) conditions. The data are shown as mean \pm SD $(n=4)$, and asterisks indicate the values which are not significantly different between the two conditions in each peanut genotype.

\section{Determination of reducing sugar content in kernels}

Kernels of five R5 seeds were homogenized together in distilled water. By dinitrosalicylic acid method, the extracts were quantified for reducing sugar content in terms of glucose equivalents (mg)/g kernel fresh weight. The experiments were performed in four replicates.

\section{Statistic analysis}

The sample mean was analyzed with Duncan's Multiple Range Test (DMRT) at 95\% confidence interval by SPSS Statistics (ver. 11.5, Chicago, IL).

\section{RESULTS}

\section{Characteristics of leaf adaptation to drought stress}

ICGV 98300 and ICGV 98308 showed better characteristics due to higher SCMR and lower SLA compared with Tainan 9 (Fig. 1). SCMR adaptation of these genotypes indicated drought establishment at both R3 and R5 stages. According to SLA, ICGV 

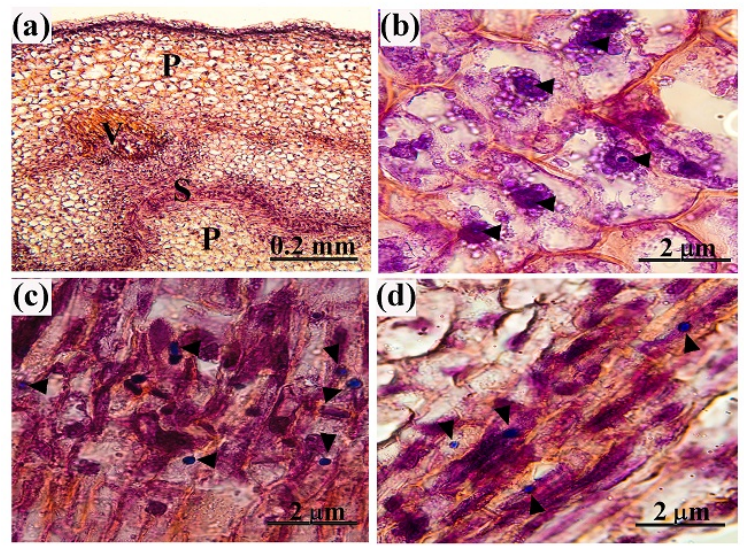

Fig. 2 Fungal proliferation in the R3 pod of a representative drought-stressed peanut plant. Photomicrographs are of ICGV 98300 as follows: (a) pericarp overview showing parenchymal layers-P, vascular bundle-V, and sclerenchyma-S; (b) outer parenchyma; (c) vascular bundle; and (d) sclerenchyma. The arrows indicate fungal stains.

98300 exhibited higher leaf thickess, and hence lower drought impact, than ICGV 98308 and Tainan 9 , respectively.

\section{Fungal infestation in pods}

The photomicrographs of drought-stressed ICGV 98300 preparations were representatives of the R3 pods having only pericarp components as usual (Fig. 2a). The blue-stained fungal features were round or ovoid, likely due to the mycelial plane in the tissue. The fungal stains were visible in the cells of outer parenchyma, vascular bundles and sclerenchyma (Fig. 2b-d). The fungus was not yet detectable in the inner parenchyma. The fungal ingresses were similar in the other two genotypes under the drought condition, and in three genotypes under the control watering (data not shown).

The R5 pod contained one beginning seed with newly developing seed coat in contact with kernel (Fig. 3e and Fig. 4c). Fungal invasion was not different in the R5 pod of the three genotypes under drought impact, of which ICGV 98308 was the representative herein. The elongated fungal stains were found in both pericarp and kernel (Fig. 3b-f). In control treatment, the fungus was not detectable in the inner parenchyma of pericarp and the young seed, as represented by the results in Tainan 9 (Fig. 4). It likely showed the defensive effect of schlerenchymal tissue.
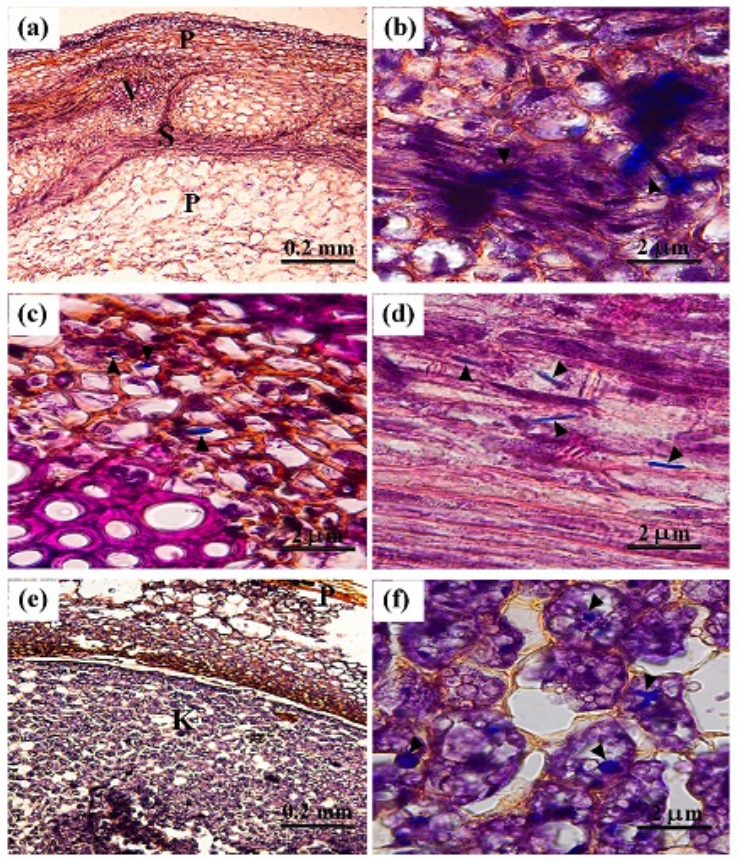

Fig. 3 Fungal proliferation in the R5 pod of a representative drought-stressed peanut plant. Photomicrographs are of ICGV 98308 as follows: (a) pericarp overview showing parenchymal layers-P, vascular bundle$\mathrm{V}$, and sclerenchyma-S; (b,c,d) pericarp focusing at outer parenchyma,vascular bundle and sclerenchyma, respectively; (e) beginning seed overview with kernel-K, surrounded by seed coat in connection with parenchyma-P; and (f) kernel. The arrows indicate fungal stains.

\section{Detection of A. flavus infection in mature seeds at harvest maturity}

There were no mycelium growth on PDA of R8 seeds from the peanuts in control experiments (Fig. 5a). Meanwhile, mycelia producing A. flavus characteristic spores were extensive in cases of seeds from the drought treated plants (Fig. 5b).

\section{Evaluation of nor-1 transcript in kernels of beginning seeds}

The base sequence of the expected 350-bp fragment (Fig. 6a) was 73\% identical to A. flavus nor-1 cDNA sequence. A non-specific 750-bp band was associated with drought in resistant genotypes. Occasional detection of nor-1 transcripts was found in the R5 kernel of the three genotypes in the control plants. When compared with Tainan 9, it was 0.8 and 1.3 folds in ICGV 98300 and ICGV 98308, respectively (Fig. 6b). The expression of nor-1 gene 

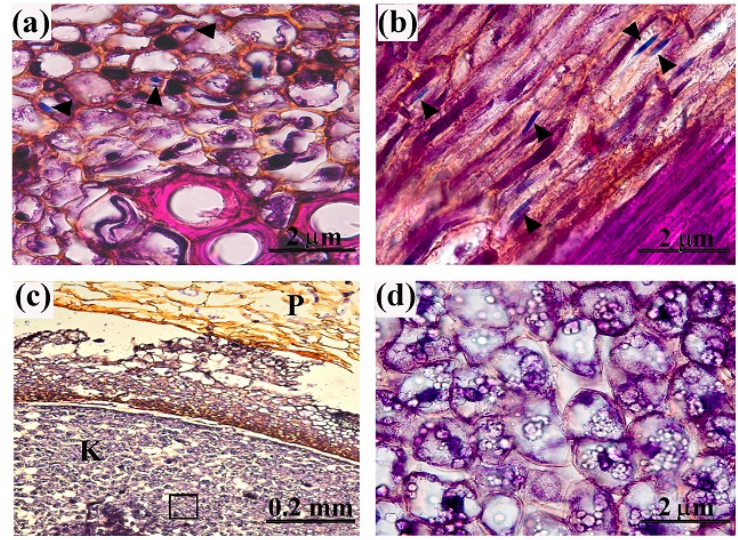

Fig. 4 Fungal proliferation in the R5 pod of a representative control peanut plant. Photomicrographs are of Tainan 9 as follows: (a) pericarp focusing at vascular bundle; (b) sclerenchyma; (c) beginning seed overview with kernel-K, surrounded by seed coat next to parenchyma-P; and (d) kernel focused at the defined rectangular area in the figure (c). The arrows indicate fungal stains.
Tainan 9
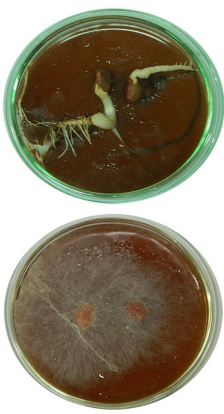

ICGV 98300

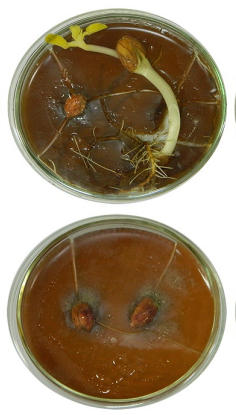

ICGV 98308
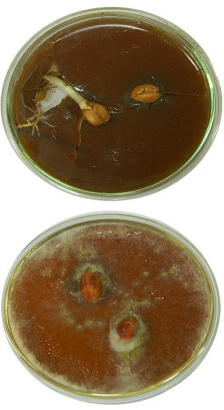

Fig. 5 Test for A. flavus contamination in seeds at harvest maturity from (a) control and (b) drought-stressed peanut plants.

was stimulated by drought to the highest level in Tainan 9, while it was induced to an insignificantly different extent in ICGV 98300 and ICGV 98308. With relation to those of the control condition, the expression was raised to 2.5 folds in Tainan 9 and ICGV 98300 but only 1.2 folds in ICGV 98308.

\section{Reducing sugar content in kernels of beginning seeds}

Of the control plants, the reducing sugar content, as glucose equivalents, was $10.51 \pm 1.38,8.22 \pm 0.19$, and $13.3 \pm 0.75 \mathrm{mg} / \mathrm{g}$ fresh weight of kernels of Tainan 9, ICGV 98300, and ICGV 98308, respec- (a)

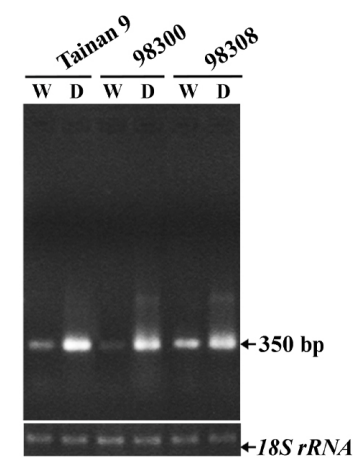

(b)

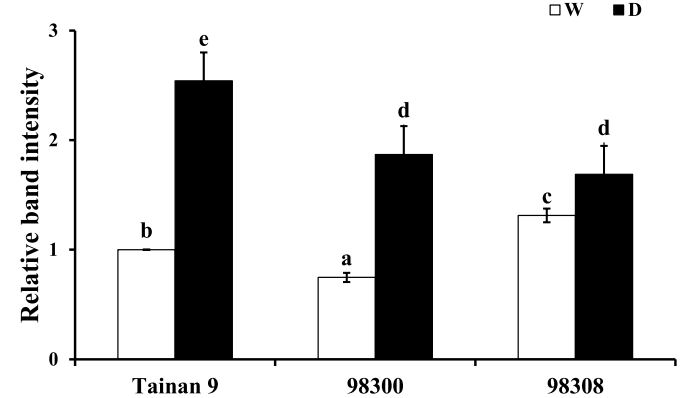

Fig. 6 Analysis for A. flavus nor-1 expression in the kernels of R5 peanut seeds: (a) RT-PCR products with that of $18 S$ rRNA normalization; (b) relative band intensities of the 350-bp target product, and the values with the same letter are not significantly different (mean $\pm S D, n=3$ ). The seed kernels were from the control (W) and droughtstressed (D) peanuts.

tively (Fig. 7). Kernel sugar was not raised its content in the drought affected ICGV 98308 plants while it was increased to the level insignificantly different in ICGV 98300 but significantly different in Tainan 9 when compared with ICGV 98308.

\section{DISCUSSION}

In this study with pot experiments, Tainan 9 was investigated in comparison to drought resistant peanut genotypes including ICGV 98300 and ICGV 98308. Tainan 9 seldom had resistant characters under field conditions [28]. The SLA data (Fig. 1) informed that Tainan 9 did not adapt leaf thickness to drought exhibiting the sensitive response. Previous pot experiments under drought also demonstrated the negative response of Tainan 9 root systems for 


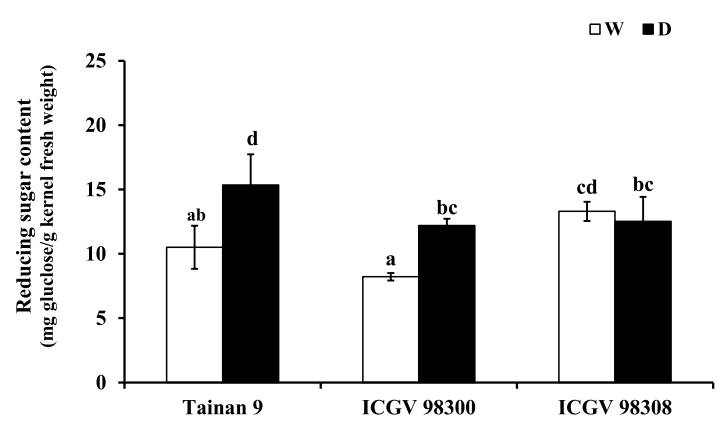

Fig. 7 Content of reducing sugar in the kernels of R5 peanut seeds. The analyses were performed with four replicates and the amount was calculated as glucose equivalents. The values with the same letter are not significantly different (mean $\pm S D, n=4$ ). The seed kernels were from the control (W) and drought-stressed (D) peanuts.

soil water uptake; meanwhile, those of ICGV 98308 and ICGV 98300 were less affected [29]. These genotypes were different in the drought impact at the whole plant level. The present work gave evidence of $A$. flavus challenged peanut pod histology at the reproductive stages, as young as R3 (beginning pod: in Fig. 2) and R5 (beginning seed: in Fig. 3 and Fig. 4), in association with drought or non-stressed control conditions. There is still a gap of knowledge of $A$. flavus colonization and virulence in the pod at both subsequent stages (R3 and R5) [22], which are different in structural and chemical components according to the progress of maturation $[13,19,30]$. It is interesting to investigate whether there are differences in fungal ingress through these stages regarding peanut genotypes and water status. Soil A. flavus could invade peg $[15,22]$ wounding promoted the infection [11]. Soil dryness could bring about injury to peg tissue. The experiments achieved drought establishment only a few days prior to R3 stage. Therefore, the peg was presumably not wounded during elongation and penetration through soil at the R2 stage, which was about seven days earlier. In this study, A. flavus virulence, as early as R3 stage, was influenced especially by drought without wounding effect on peg.

Pericarp, or shell, accounts for the majority of R3 pod tissue, which is soft and full of vascular systems $[19,21]$. During pod maturation, pericarp distributes nutrients from leaf sources to the seed embryo sink while it becomes continually dehydration. Resistance to shell infection at the young pod stage might be a primary mechanism of resistance to aflatoxin contamination in seed kernel $[13,14]$. Sclerenchymal layer of the young pod has been proposed to function as a barrier to fungal invasion in general because it is the pericarp component containing dead cells with abundant lignin deposition in secondary wall [30]. Lignin is a kind of polyphenolic compounds having antifungal activity, and immense lignification makes sclerenchyma a hard zone. Histological investigations of R3 pods illustrated the dispersion of fungal ingress in several parts of pericarp to the distance of sclerenchymal layer (Fig. 2). The A. flavus virulence was not different in expanding mycelium in the pericarp of this pod stage with regard to either water status or genotype. It was presumed that the mycelial growth could be opposed by the physical and chemical architectures of sclerenchyma, which was still effective during a few days prior to the onset of drought at the R3 stage. When pods proceeded to R5 stage under drought treatment, the fungal virulence was vigorous, as the mycelia could be found in kernel of the beginning seed (Fig. 3). Drought should, somehow, cause the accumulative impairment of sclerenchyma in R5 pods in drought resistant genotypes (ICGV 98300 and ICGV 98308) as well as the sensitive genotype (Tainan 9). Without the stress, A. flavus retained in the pericarp outer parenchyma demonstrating the active sclerenchyma function (Fig. 4). The beginning seed contains seed coat with its formation initiated in advance at R4 stage [19]. Mature seed coat is a defense structure and a resistant mechanism for A. flavus seed colonization because it is constitutively rich in waxes and antibiotic polyphenols including tannins [13]. Maturity is at R7 (beginning seed maturity) stage when seed coat is visibly red or brown pigmented by tannin accumulation [19]. This information supported the importance of sclerenchyma and efficient water supply in coping with $A$. flavus virulence in R3 and R5 pod stages. The role of sclerenchyma was not shown, herein, to associate with drought resistant trait at the whole plant system; otherwise, more resistant genotypes should be subjected to similar study. As in Fig. 5, R8 seeds of control plants generated normal seedlings without $A$. flavus emergence. The fungal colonization was suppressed in those seeds. It might be due to the involvement of healthy seed coat [13] and kernel phytoalexins [31] during seed maturation, when pericarp became dehydrated and could be more vulnerable to A. flavus penetration. Then, drought could destroy the functions of seed coat defensive components (waxes 
and polyphenols) and kernel phytoalexins either in drought resistant or sensitive genotypes. Histological studies in R5 pods and tests for contamination in mature seeds gave evidence for $A$. flavus-free seed kernel under efficient water supply, as compared to the drought-activated A. flavus colonization.

A. flavus infection was found in a number of seeds of the peanuts grown under non-drought and largely increased by drought [10]. The kernels of beginning seed in R5 pods from control and drought-stressed plants were studied for another viewpoint of $A$. flavus virulence, i.e. aflatoxin synthesis, by detecting the expression of nor-1 (or aflD) gene, which is a determinant gene in the synthetic pathway [4]. The amount of nor-1 transcript was dependent on genotypes and soil water management (Fig. 6). The nor-1 transcript could be found in the kernels of juvenile seeds from control plants, too. It helped comparatively determine the effect of drought. Peanut kernel (or embryo cotyledon) consists of abundant amount of sucrose, small content of non-reducing sugars, and two reducing sugars (glucose and fructose) [32]. Besides sucrose, glucose and fructose are more preferable precursors than fatty acids for aflatoxin synthesis. It has been found that sugars functioned as transcription factors in aflatoxin gene cluster induction [2]. A. flavus produces the toxin when it grows in the environment of these sugars. On another hand, reducing sugars showed a role in balancing the level of reactive oxygen species caused by cellular activity or oxidative stress in plants [33]. The virulence of A. flavus in aflatoxin B1 production is enhanced by plant generating oxidative compounds, such as hydrogen peroxide and lipid hydroperoxides, which stimulate transcription factor binding to promoters of genes in the aflatoxin gene cluster [2,34]. Therefore, increased reducing sugar content in kernel may have either positive or negative effect on aflatoxin production. In the current study, we were interested in the involvement of reducing sugars in aflatoxin production, and wanted to find out whether the production was elevated or not under the oxidative stress due to drought effect [35]. In the control groups, the content of reducing sugars was genotype dependent (Fig. 7), which may reflect the differences in oxidative background of seed kernels, being relatively high in ICGV 98308. Drought similarly augmented the reducing sugar accumulation in kernels of R5 seeds from Tainan 9 and ICGV 98300 which positively correlated with the increment profile of nor-1 transcripts (Fig. 6). The nor-1 expression was slightly activated by drought in IGGV
98308; however, the effect was not observed for the reducing sugar content. It seemed that the oxidative stress was manipulated by other mechanisms, such as anti-oxidative enzymes [2]. Leaf traits, including SCMR and SLA, were proposed to associate with resistance to drought and preharvest aflatoxin contamination $[10,17]$. Notably, advantageous adaption of both traits to drought (Fig. 1) did not definitely predict resistance to A. flavus virulence in aflatoxin synthesis in the kernel of drought resistant peanut genotypes. The evidence of drought induction on nor-1 gene expression and reducing sugar content was significant for the ICGV 98300 genotype. Moreover, it was previously reported that drought raised aflatoxin level in R8 seed kernels of ICGV 98300 and ICGV 98308 to as high as the level of Tainan 9 grown under field conditions [10].

\section{CONCLUSION}

A. flavus occupied peanut pod pericarp at the beginning of pod formation (R3) regardless of genotypes, whether drought sensitive (Tainan 9) or resistant (ICGV 98300 and ICGV 98308), and conditions of soil water. Pericarp sclerenchyma was shown as a primary barrier against $A$. flavus invasion. The fungal colonization in mature seeds (R8) might be due to the loss of sclerenchyma of the beginning seed (R5) caused by drought independently on genotypes. The nor-1 gene expression in aflatoxin synthesis was occasionally detectable in the kernels of R5 seeds of non-stressed plants. With exception to ICGV 98308, the gene expression was relatively low when the content of kernel reducing sugars was also low. Drought enhanced the toxin synthesis by promoting the fungal gene expression and the kernel sugar accumulation. ICGV 98308 exhibited a resistant genotype of which aflatoxin synthesis should be high under water regimes for control and drought-stressed plants under greenhouse conditions.

Acknowledgements: The authors are grateful to the Higher Education Research Promotion and National Research University Project of Thailand, Office of the Higher Education Commission, through the Food and Functional Food Research Cluster of Khon Kaen University, Thailand, for funding under the Grant No. NRU541007. Thanks are also given to the Peanut and Jerusalem Artichoke Improvement for Functional Food Research Group and the Plant Breeding Research Center for Sustainable Agriculture, Khon Kaen University, for facilities in planting and collecting data on peanut physiology. 


\section{REFERENCES}

1. Hedayati MT, Pasqualotto AC, Warn PA, Bowyer P, Denning DW (2007) Aspergillus flavus: human pathogen, allergen and mycotoxin producer. Microbiology 153, 1677-1692.

2. Caceres I, Khoury AA, Khoury RE, Lorber S, Oswald IP, Khoury AE, Atoui A, Puel O, et al (2020) Aflatoxin biosynthesis and genetic regulation: A review. Toxins 12, ID 150.

3. Zain ME (2011) Impact of mycotoxins on humans and animals. J Saudi Chem Soc 15, 129-144.

4. Bhatnagar D, Cary JW, Ehrlich K, Yu J, Cleveland TE (2006) Understanding the genetics of regulation of aflatoxin production and Aspergillus flavus development. Mycopathologia 162, 155-166.

5. Kew MC (2003) Synergistic interaction between aflatoxin B1 and hepatitis B virus in hepatocarcinogenesis. Liver Int 23, 405-409.

6. Ernuo T, Xin D, Wenhao C, Changgao W, Jianguo L, Cai J (2020) Structure and toxicity analysis of aflatoxin B1 biodegraded products by culture supernatant of Cladosporium uredinicola. ScienceAsia 46, 308-314.

7. Fageria NK, Baligar VC, Jones CA (2010) Peanuts. In: Fageria NK, Baligar VC, Jones CA (eds) Growth and Mineral Nutrition of Field Crops 3rd edn, CRC Press, Taylor\&Francis Group, Boca Raton, pp 425-435.

8. Thiessen LD, Woodward JE (2012) Diseases of peanut caused by soilborne pathogens in the southwestern United States. ISRN Agronomy 2012, 1-9.

9. Reddy TY, Reddy VR, Anbumozhi V (2003) Physiological responses of groundnut (Arachis hypogaea L.) to drought stress and its amelioration: a critical review. Plant Growth Reg 41, 75-88.

10. Arunyanark A, Jogloy S, Wongkaew S, Akkasaeng C, Vorasoot N, Wright GC, Rachaputi RCN, Patanothai A (2009) Association between aflatoxin contamination and drought tolerance traits in peanut. Field Crops Res 114, 14-22.

11. Horn BW (2005) Colonization of wounded peanut seeds by soil fungi: selectivity for species from Aspergillus section Flavi. Mycologia 97, 202-217.

12. Torres AM, Barros GG, Palacios SA, Chulze SN, Battilani P (2014) Review on pre- and post-harvest management of peanuts to minimize aflatoxin contamination. Food Res Int 62, 11-19.

13. Liang XQ, Luo M, Guo BZ (2006) Resistance mechanisms to Aspergillus flavus infection and aflatoxin contamination in peanut (Arachis hypogaea). Plant Pathol J 5, 115-124.

14. Olwari F, Bisikwa J, Kaaya AN, Okello DK (2013) Tolerance levels of peanut varieties against Aspergillus flavus infection. $J$ Plant Pathol Microb 4, 1-4.

15. Puntase J, Senthong C, Ingram KT, Weissinger AK (2006) Identification of infection pathways and development of inoculation methods for peanut using green-fluorescence-protein Aspergillus flavus. Agric $J$ 1, 141-148.

16. Shan SH, Wang HX, Li CJ, Wan SB, Liu HT, Jiang GY (2006) Research of seed testa structure and storage material of peanut germplasm with different resistance to A. flavus. Agric Sci China 5, 478-482.

17. Girdthai T, Jogloy S, Vorasoot N, Akkasaeng C, Wongkaew S, Holbrook CC, Patanothai A (2010) Associations between physiological traits for drought tolerance and aflatoxin contamination in peanut genotypes under terminal drought. Plant Breed 129, 693-699.

18. Hamidou F, Rathore A, Waliyar F, Vadez V (2014) Although drought intensity increases aflatoxin contamination, drought tolerance does not lead to less aflatoxin contamination. Field Crops Res 2014, 103-110.

19. Boote KJ (1982) Growth stages of peanut (Arachis hypogaea L.). Peanut Sci 9, 35-40.

20. Pattee HE, Johns EB, Singleton JA, Sanders TH (1974) Composition changes of peanut fruit parts during maturation. Peanut Sci 1, 57-62.

21. Xu H, Annis S, Linz J, Trail F (2000) Infection and colonization of peanut pods by Aspergillus parasiticus and the expression of the aflatoxin biosynthetic gene, nor-1, in infection hyphae. Physiol Mol Plant Pathol 56, 185-196.

22. Souza GF de, Mossini SAG, Arrotéia CC, Kemmelmeier C, Junior MM (2014) Evaluation of the mycoflora and aflatoxins from the preharvest to storage of peanuts: a case study. Acta Sci Agron 36, 27-33.

23. Songsri P, Jogloy S, Holbrook CC, Kesmala T, Vorasoot N, Akkasaeng C, Patanothai A (2009) Association of root, specific leaf area and SPAD chlorophyll meter reading to water use efficiency of peanut under different available soil water. Agric Water Manag 96, 790-798.

24. Rittenour WR, Harris SD (2012) In vitro induction of infection-related hyphal structures in plant pathogenic fungi. In: Bolton MD, Thomma BPHJ (eds) Plant Fungal Pathogens: Methods and Protocols, Methods in Molecular Biology 835, Humana Press, USA, pp 377-383.

25. Marques JPR, Soares MKM, Appezzato-da-Gloria B (2013) New staining technique for fungal-infected plant tissues. Turk $J$ Bot 37, 784-787.

26. Scherm B, Palomba M, Serra D, Marcello A, Migheli Q (2005) Detection of transcripts of the aflatoxin genes aflD, aflO, and aflP by reverse transcriptionpolymerase chain reaction allows differentiation of aflatoxin-producing and non-producing isolates of Aspergillus flavus and Aspergillus parasiticus. Int $J$ Food Microbiol 98, 201-210.

27. Sambrook JE, Fritsch EF, Maniatis T (1989) Gel electrophoresis. In: Ford N, Nolan C, Ferguson M (eds) Molecular Cloning: A Laboratory Manual, 2nd edn, Cold Spring Harbor Laboratory Press, New York, pp 6.3-6.5. 
28. Mamadou CA, Ntare B, Gracen V, Danquah EY, Ofori K (2017) Evaluation of groundnut mini core to identify sources of tolerance to end of season drought in the Sahel, Niger. Int. J. Plant Breed. 11, 31-38.

29. Junjittakarn J, Girdthai T, Jogloy S, Vorasoot N, Patanothai A (2014) Response of root characteristics and yield in peanut under terminal drought condition. Chil J Agric Res 74, 249-256.

30. Bacete L, Mélida H, Miedes E, Molina A (2018) Plant cell wall-mediated immunity: cell wall changes trigger disease resistance responses. Plant $J \mathbf{9 3}$, 614-636.

31. Sobolev V, Walk $\mathrm{T}$, Arias R, Massa A, Lamb M (2019) Inhibition of aflatoxin formation in Aspergillus species by peanut (Arachis hypogaea) seed stilbenoids in the course of peanut-fungus interac- tion. J Agric Food Chem 67, 6212-6221.

32. Ahmed EM, Young CT (1982) Composition, quality, and flavor of peanuts. In: Pattee HE, Young CT (eds) Peanut Science and Technology, APRES Inc, Texas, pp 655-688.

33. Couée I, Sulmon C, Gouesbet G, Amrani AE (2006) Involvement of soluble sugars in reactive oxygen species balance and responses to oxidative stress in plants. $J$ Exp Bot 57, 449-459.

34. Roze LV, Chanda A, Wee J, Awad D, Linz JE (2011) Stress-related transcription factor AtfB integrates secondary metabolism with oxidative stress response in Aspergilli. Int J Biol Chem 286, 35137-35148.

35. Uppala SS, Bowen KL, Woods FM (2013) Preharvest aflatoxin contamination and soluble sugars of peanut. Peanut Sci 40, 40-51. 